\title{
Clinical profile of ascites in children at tertiary care hospital, North Karnataka
}

\author{
Talawar K' ${ }^{1}$, Ramesh R Pol${ }^{2}$, Yelamali B. C. ${ }^{3}$ \\ ${ }^{1}$ Dr. Keludeppa Talawar, Assistant Professor, ${ }^{2}$ Dr. Ramesh R Pol, Associate Professor, ${ }^{3}$ Dr. B. C. Yelamali, Professor, all \\ are affiliated with Department of Pediatrics, S. Nijalingappa Medical College, Bagalkot, Navanagar, Karnataka 587 102, \\ India.
}

Address for Correspondence: Dr. Ramesh R Pol, Associate Professor, Department of Pediatrics, S. Nijalingappa Medical College, Bagalkot. Email id: rameshpol@ymail.com.

\begin{abstract}
Introduction: Ascites is a common clinical problem in children with liver and renal disease. The peripheral arterial vasodilation hypothesis is mostly accepted as the patho-physiological basis of ascites. The most important complication is spontaneous ascitic fluid infection in the form of spontaneous bacterial peritonitis (SBP) and its variants. Objective: To know the incidence, etiology, associated clinical co-morbidities \& the outcome (morbidity \& mortality) of the hospitalized children with ascites. Materials and Methods: After informed written consent from parents/ guardian, 102 children admitted with ascites irrespective of primary diagnosis were studied at department of Pediatrics, S. Nijalingappa Medical College, Bagalkot. The study was a prospective study and subjects were enrolled consecutively. Detailed history, complete physical examination \& routine investigations were done in all patients and were recorded in predesigned proforma. A detailed etiological workup was done. Results: The most common symptoms were abdominal distension (100\%), facial puffiness (62.74\%), pedal edema (46.08\%), \& generalized swelling (35.29\%). The most common signs were facial puffiness in $62.74 \%$, pedal edema in $46.07 \%$ \& anasarca in $35.29 \%$ the most common etiology of ascites was dengue fever, followed by nephrotic syndrome. Of the 102 children with ascites, 2 expired (Gaucher's disease \& Wilson's disease). Conclusion: Prompt and early diagnosis and appropriate management of ascites is warranted to prevent related morbidity and mortality in children.
\end{abstract}

Key words: Ascites in children, Etiology, Outcome, Paracentesis

\section{Introduction}

In clinical practice, the term Ascites refers to the detectable and pathological collection of fluid in the peritoneal cavity. Word Ascites is of Greek derivation [askos] which refers to a 'bag' or 'sack'. The word describes pathologic fluid accumulation within the peritoneal cavity.

Normal volume of intra peritoneal fluid is approximately $<20 \mathrm{ml}$. Ascites may consist of either transudate or exudates. There are a variety of diseases that can cause the fluid to accumulate. Ascites can occur at any age and in utero. The etiology of ascites may differ among neonates and older children. In children it is usually the result of liver, cardiac or renal

Manuscript received: $27^{\text {th }}$ April 2016

Reviewed: $10^{\text {th }}$ May 2016

Author Corrected; $25^{\text {th }}$ May 2016

Accepted for Publication: $12^{\text {th }}$ June 2016 disease [1]. Common causes of ascites in children are cirrhosis of liver, portal vein obstruction, fulminant hepatic failure, budd-chiari syndrome, nephrotic syndrome, congestive heart failure, constrictive pericarditis, tuberculosis, bowel perforation, lymphoma, pancreatitis \& chylous ascites. The precise incidence of ascites in children is unknown, but the condition is rare. This was not been extensively studied in Indian children. The purpose of this study was to know the incidence of the ascites in hospitalized children, various etiologies of it, associated clinical co-morbidities \& the outcome (morbidity \& mortality).

\section{Materials and Methods}

All children aged between 13 months to 12 years with ascites were included in the study, irrespective of their primary diagnosis admitted in pediatric ward of $\mathrm{S}$. 
Nijalingappa Medical College, Bagalkot. The study was conducted during October 2013 to March 2015 (18 months period). The study was a prospective study and subjects were enrolled consecutively till the time bound. During this study period, 102 children presented with ascites.

Detailed history, physical examination and routine investigations were done and were recorded in predesigned proforma. Protein energy malnutrition was graded as per IAP classification. Ultrasound was done in all children irrespective of their symptoms at the time of first presentation. Ascitic tap and its analysis were done after taking written consent from the guardian with full aseptic precaution. Special tests like Dengue serology, ceruloplasmin levels, TORCH profile, upper GI endoscopy, liver biopsy and bone marrow examination were done to know the etiology.

The informed written consent of parents/guardian and confidentiality was assured. Ethical committee clearance was taken before the study from the institutional research board.

\section{Results}

A total of 102 confirmed cases of ascites in children were studied during this study period. The total number of admissions in Pediatric ward during the study period was 24580 and the incidence of ascites was $0.0042 \%$. The mean age of presentation was $51 / 2$ years. The maximum cases in the study were males, constituting $61(59.81 \%)$ and females were $41(40.19 \%)$ with ratio of 1.49:1. Maximum number of patients were in the age group of 1-4 \& 5-8 years (34 children i.e. $33.33 \%$ each). According to IAP classification, $51.96 \%$ were having grade I \& $23.52 \%$ were having grade II malnutrition. Severe malnutrition (grade III \& IV) was present in only $9.8 \%$ and normal nutritional status in $14.7 \%$.

The most common symptoms were abdominal distension (100\%), facial puffiness $(62.74 \%)$, pedal edema (46.08\%), \& generalized swelling (35.29\%) (Table-I).

\section{Table -I: Symptoms.}

\begin{tabular}{|l|l|}
\hline Symptoms & No. of cases \\
\hline Abdominal distension & $102(100 \%)$ \\
\hline Puffiness of face & $64(62.74 \%)$ \\
\hline Pedal edema & $47(46.08 \%)$ \\
\hline Fever & $42(41.17 \%)$ \\
\hline Generalized swelling of body & $36(35.29 \%)$ \\
\hline Breathlessness & $29(28.43 \%)$ \\
\hline Pain abdomen & $23(22.55 \%)$ \\
\hline Cough & $23(22.55 \%)$ \\
\hline Reduced urine output & $21(20.59 \%)$ \\
\hline Vomiting & $17(16.67 \%)$ \\
\hline Weight loss & $16(15.69 \%)$ \\
\hline Jaundice & $12(11.76 \%)$ \\
\hline Generalised rash & $12(11.76 \%)$ \\
\hline Red urine & $7(6.86 \%)$ \\
\hline Convulsions & $5(4.9 \%)$ \\
\hline Haematemesis & $5(4.9 \%)$ \\
\hline Bleeding per rectum & $4(3.9 \%)$ \\
\hline
\end{tabular}


Table- II: Signs.

\begin{tabular}{|l|l|}
\hline Signs & No. of cases \\
\hline Abdominal distention & $102(100 \%)$ \\
\hline Puffiness of face & $64(62.74 \%)$ \\
\hline Pedal edema & $47(46.08 \%)$ \\
\hline Anasarca & $36(35.29 \%)$ \\
\hline Pallor (moderate to severe) & $22(21.57 \%)$ \\
\hline Genital edema & $21(20.59 \%)$ \\
\hline Petechiae & $17(16.67 \%)$ \\
\hline Icterus & $13(12.74 \%)$ \\
\hline Rash & $12(11.76 \%)$ \\
\hline Clubbing & $11(10.78 \%)$ \\
\hline Cervical lymphadenopathy & $7(6.86 \%)$ \\
\hline Signs of shock & $3(2.94 \%)$ \\
\hline Signs of hepatic failure* & $1(0.98 \%)$ \\
\hline
\end{tabular}

*hepatic encephalopathy

Table- III: Etiology.

\begin{tabular}{|l|l|l|l|}
\hline \multirow{2}{*}{ Etiology } & $\begin{array}{l}\text { No. of patients } \\
\text { (n=102) }\end{array}$ & \% \\
\hline Dengue Fever & 38 & 37.23 \\
\hline Nephrotic syndrome & 33 & 32.35 \\
\hline Abdominal tuberculosis & Wilson's disease with portal hypertension & 9 & 8.80 \\
\cline { 2 - 3 } Chronic liver disease & Wilson's disease without portal hypertension & 1 & \multirow{2}{*}{8.80} \\
\cline { 2 - 3 } & Gaucher's disease with portal hypertension & 1 & \\
\cline { 2 - 3 } & Unknown & 6 & 2.94 \\
\hline Acute infective hepatitis & CMV & 3 & 2.94 \\
\hline Extra hepatic portal hypertension & 3 & 2.94 \\
\hline \multirow{3}{*}{ TORCH } & Rubella & 2 & 1.96 \\
\hline \multicolumn{2}{|l|}{ Post-streptococcal glomerular nephritis } & 2 & 0.98 \\
\hline \multicolumn{2}{|l|}{ Enteric fever } & 1 & 0.98 \\
\hline \multicolumn{2}{|l|}{ Congenital lymphangiectasia syndrome } & 1 & \\
\hline
\end{tabular}

*One patient had congenital Nephrotic syndrome due to congenital CMV infection.

The most common signs were facial puffiness in (62.74\%), pedal edema (46.08\%), \& anasarca in $35.29 \%$ (Table- II).

Positive family history of Wilson's disease was present in elder sibling of one child. Maternal history of CMV was present in one infant. On clinical examination, isolated ascites was detected in $57.83 \%$ of patients; whereas accompanying hepatomegaly \& spleno-hepatomegaly were present in $26.47 \%$ \& $6.86 \%$ respectively. Diagnostic ascitic tap was done in 48 patients, off which it was clear in $70.83 \%$. In 8 patients the fluid was hazy in appearance, suggestive of possibly infective origin because there was elevated protein $(2.5 \mathrm{gm})$ and cells ( $>500 \mathrm{cells})$. One patient had milky (chylous) appearance of ascitic fluid. In $83.33 \%$ ascitic fluid was transudative, whereas in $16.67 \%$ it was exudative in nature. All with exudative fluid had lymphocyte predominant.

Ultrasound of abdomen of these children had only ascites in $28(27.5 \%)$ children. Of the 28 children, 26 children had nephrotic syndrome and $25.5 \%$ patients showed ascites $\&$ hepatomegaly with normal echo- texture (primary diagnosis 
was Dengue fever in most). 13 (12.75\%) patients had altered hepatic echotexture of which $6(5.88 \%)$ had reduced liver size (primary diagnosis was Chronic Liver Disease). 3 (2.94 \%) patients had ascites, splenomegaly with normal liver size \& echotexture.

KF ring on slit lamp examination, elevated urinary copper \& reduced serum ceruloplasmin were present in 2 patients, which is suggestive of Wilson's disease. One patient who presented with ascites, portal hypertension \& hepatomegaly had bone marrow aspiration suggestive of storage disorder- Gaucher's disease. Liver biopsy was planned in 6 patients of undiagnosed chronic liver disease. Biopsy of these patient showed, PAS positive hepatocytes with diastase positive suggestive of chronic liver disease. Colour Doppler examination showed changes of extra hepatic portal hypertension in $3 \&$ intra hepatic portal hypertension in 2. Upper GI endoscopy was done in two patients which showed varices in lower oesophageal \& fundus of stomach suggestive of portal hypertension. Serological test for TORCH infection were positive in three (CMV IgG \& IgM in 2 \& Rubella IgM in 1).

Based on history, clinical examination and investigations, the most common etiology of ascites was Dengue fever, followed by nephrotic syndrome (Table -III). Of the 102 children with ascites, 2 expired, among them one was Gaucher's disease $\&$ the other was Wilson's disease.

\section{Discussion}

Ascites, defined as fluid accumulation in the peritoneal cavity, may accompany several diseases. Patients who suffer from ascites present with diagnostic and therapeutic difficulties [2-4]. Biochemicals, microbiological and cytological analysis of ascitic fluid are very important for etiological diagnosis of ascites. Traditionally, ascites has been classified as being either transudative or exudative, based upon the ascitic fluid total protein concentration $[5,6]$, the ascitic fluid to serum ratio of total protein $[7,8]$ or the ascitic fluid to serum ratio of lactic dehydrogenase [9].

The accumulation of ascitic fluid represents a state of total body sodium and water excess, but the event that initiates the imbalance is unclear. Three theories of ascites formation have been proposed: underfilling, overflow, and peripheral arterial vasodilation. Exact incidence of ascites in children is not known, but in a study conducted by Seth V et al, at a teaching institute attached with tertiary care hospital, incidence was found to be $0.0016 \%$ [10]. The reason for low incidence could be universal immunization against tuberculosis \& hepatitis B, which may have lead to decreasing incidence of disseminated form of tuberculosis \& chronic hepatitis respectively. Due to increasing awareness \& actions on prevention of neonatal sepsis, there is reduced incidence of umbilical sepsis (which is an important cause of portal vein obstruction \& extrahepatic portal hypertension).

Maximum numbers of patients were in the age group of 1-4 \& 5-8 years (33.33\% each). Runyon BA et al studies showed that maximum number of patients were in the age group of 1-8 years (11). High incidence in this age may be related to frequent occurrence of nephrotic syndrome and increasing incidence of dengue fever.

The most common symptoms were facial puffiness (62.74\%), pedal edema $(46.08 \%), \&$ generalized swelling $(35.29 \%)$. Basu $\mathrm{S}$ et al reported that most common symptom was abdominal distension (100\%) followed by pain abdomen $(90.43 \%) \&$ fever $(73.04 \%)$ [12]. Aggarwal et al showed that most common symptom was abdominal distension (100\%) followed by fever (93\%) \& vomiting (68\%) [13]. Chopra et al reported that most common symptom was abdominal distension (100\%) followed by pain abdomen (83\%), jaundice (66.7\%) \& vomiting (62\%) [14].

Causes of generalized fluid retention are hypoproteinemia, anemia, congestive heart failure \& capillary leak. Breathlessness (28.4\%) \& oliguria (20.59\%) may be consequent to fluid retention.

Fever was the most common constitutional symptom (41.17\%) followed by weight loss (15.69\%). Fever accompanying with generalized rash was present in $11.76 \%$. Fever \& rash when associated with fluid retention, it may suggest that illness like Dengue fever is likely. Jaundice was present in $11.76 \%$. Haematemesis (4.9\%) \& malena (3.9\%) along with ascites that suggest portal hypertension were present in five patients, of which two patients had both manifestations. Convulsion with altered sensorium was present in $4.9 \%$ which suggest encephalopathy. Red urine $(6.86 \%)$ could be related to renal dysfunction (nephritis) or bleeding disorder. 
Out of all patients, $51.96 \%$ were having grade I \& $23.52 \%$ were having grade II malnutrition. Severe malnutrition (grade III \& IV) was present in only $9.8 \%$. Basu $\mathrm{S}$ et al reported that $33.04 \%$ of patients had grade II malnutrition \& $26.96 \%$ had grade III malnutrition [12]. This suggests that there was no association between ascites \& poor nutrition.

Isolated ascites was detected in $57.83 \%$ of patients, where as accompanying hepatomegaly \& splenohepatomegaly was present in $26.47 \%$ \& $6.86 \%$ respectively. Aggarwal A et al reported isolated ascites in $41 \%$ \& ascites with hepatomegaly in $30 \%$ [13].

Ultrasound is a sensitive imaging technique for the detection of ascites. Free fluid can be imaged confidently with ultrasound because it layers in the dependent regions, the hepato-renal recess (Morison pouch) and the pelvic cul-de-sac [15]. It has been estimated that in infants/ children even 10 to $20 \mathrm{ml}$ free fluid can be detected by ultrasound in the perivesicle area [16].

In most children, ascites is readily recognizable as caused by hepatitis, portal hypertension, or nephrotic syndrome. When the cause of ascites is not known, examination of ascitic fluid can aid in identification of the etiology. Abdominal paracentesis is recommended to detect bacterial peritonitis, when patients are hospitalized because of clinical deterioration, or when the patient has fever or abdominal pain [3].

Diagnostic ascitic tap was done in 48 patients, off which it was clear in $70.83 \%$. In 8 patients the fluid was hazy in appearance, suggestive of possibly infective origin because there was elevated protein $(2.5 \mathrm{gm})$ and cells ( $>500$ cells). One patient had milky appearance of ascitic fluid that suggests chylous nature of it. Runyon BA et al showed $25 \%$ clear fluid \& $50 \%$ pale yellow [11]. In $83.33 \%$ ascitic fluid was transudative, whereas in $16.67 \%$ it was exudative in nature. All with exudative fluid had lymphocyte predominant whereas in a study conducted by Runyon BA et al showed that 25 $\%$ of them had exudative fluid [11].

The most common etiology of ascites in our study was Dengue fever $(37.20 \%)$, followed by nephrotic syndrome $(32.35 \%)$, abdominal tuberculosis $(8.80 \%)$ and chronic liver disease $(8.80 \%)$. Runyon BA et al showed Chronic liver disease (37.5\%), nephrotic syndrome $(25 \%)$, abdominal tuberculosis $(25 \%) \&$ rheumatic fever $(12.5 \%)$ as etiologies for ascites [11]
Chopra $\mathrm{K}$ et al reported that cirrhosis of liver (23.9\%) as the most common etiology for ascites [14]. According to Thomas JR et al, the etiologies of ascites are cirrhosis of liver (16\%), extra-hepatic portal hypertension (6\%), abdominal tuberculosis (15\%) \& nephrotic syndrome $(30 \%)$ [17].

Bacterial peritonitis is a complication of ascites with a high mortality rate if treatment is delayed. The incidence of spontaneous bacterial peritonitis (SBP) in children is not known [18]. In a report of 321 children with chronic liver disease, there were 12 episodes of SBP in 11 patients; all 11 had ascites [19]. Cultures of ascitic fluid detected a single organism in 11 of the episodes; Streptococcus pneumoniae was isolated in $73 \%$, Klebsiella pneumoniae in $18 \%$, and Hemophilus influenzae in 9\%. A more recent report examined 13 culture-positive cases of SBP in 12 pediatric patients. Isolated organisms were $\mathrm{S}$ pneumoniae (39\%), Escherichia coli (15\%), $\mathrm{S}$ viridans (15\%), $\mathrm{K}$ pneumoniae, $\mathrm{H}$ influenzae, Enterococci, and nontypable Streptococcus [20]. The declining prevalence of Streptococcus and Haemophilus in this pediatric series likely reflects contemporary vaccination protocols. It is recommended that diagnostic paracentesis be performed when ascites first appears, at the time of a hospitalization, or when there is clinical deterioration, unexplained fever, abdominal pain, or other suspicious symptoms.

The prognosis for patients with ascites especially liver disease depends on the underlying disorder, the degree of reversibility of a given disease process, and the response to the treatment.

\section{Conclusion}

The pediatric population has a number of unique considerations related to the diagnosis and treatment of ascites. Understanding of the pathophysiology and possible etiologies of pediatric ascites is critical in making a rapid diagnosis of this condition. This study provides the common etiologies (Dengue fever and nephrotic syndrome) in children with ascites. Characteristic findings on physical examination, diagnostic imaging, and abdominal paracentesis were studied, which showed renal involvement and capillary leak was the commonest etiology. Early and prompt diagnosis with appropriate management could prevent morbidity and mortality.

Funding: Nil, Conflict of interest: Nil Permission from IRB: Yes 


\section{References}

1. Giefer MJ, Murray KF, Colletti RB. Pathophysiology, Diagnosis, and Management of Pediatric Ascites.J Pediatr GastroenterolNutr2011;52(5):503-513.

2. Hoefs JC, Jonas GM. Diagnostic paracentesis. Adv Int Med 1992; 37:391- 409.

3. Runyon BA. Care of patients with ascites. N Engl J Med 1994; 330:337-42.

4. Runyon BA. Ascites and spontaneous bacterial peritonitis. In Sleisenger MH, Fordtran JS, eds. Gastrointestinal diseases: pathophysiology, diagnosis, management, Vol II. Philadelphia: W.B. Saunders Company, 1993; 1977-2003.

5. Paddock FK. The diagnostic significance of serum fluid in disease. N Engl J Med 1940; 223: 1010-5.

6. Rovelstad RA, Bartholomew LA, Cain JC, et al. The value of examination of ascitic fluid and blood for lipids and for proteins by electrophoresis. Gastroenterology 1958; 34:436-50.

7. Light R, MacGregor M, Lucksinger P, Ball WC Jr. Pleural effusion: the diagnostic separation of transudates and exudates. Ann Intern Med 1972; 77:507-13.

8. Boyer TD, Kahn AM, Reynolds TB. Diagnostic value of ascetic fluid dehydrogenase, protein and white blood counts levels. Arch Intern med 1978; 138:1103-5.

9. Sampliner ME, Iber FL. High protein ascites in patients with uncomplicated hepatic cirrhosis. Am J Med Sci 1974; 267:275-9.

10. Seth V, Kabra SK. A clinical study of ascites in Children with special referance to Serum Ascitic Albumin Gradient. Essentials of Tuberculosis in children, 3rd edition; pg 143-53.

11. Runyon BA, Montano AA, Alkriviadis EA, Antillon MR, Irving MA, McHutchison JG The serum-ascites albumin gradient is superior to the exudate-transudate concept in the differential diagnosis of ascites. Ann. Intern. Med. 1992; 117:215 219.

12. Basu S, Ganguly S, Chandra PK, Basu S. Clinical profile and Outcome of abdominal tuberculosis in Indian children. Singapore Med J 2007; 48:900-5.

13. Aggrawal A, Chandra J, Aneja S, Patwari AK, Dutta AK. An Epidemic of Dengue Hemorrhagic Fever and Dengue Shock Syndrome in Children in Delhi. Indian pediatrics $1998 ; 35 ; 727-32$.

14. Chopra K, BP Kalra, Indu S, Zeeba ZR: Clinicopathological profile of children with Liver disease with Ascites. Curr Pediatric Research2008; 12 (1\&2): 39 -41

15. Nguyen KT, Sauerbrei EE, Nolan RL. The peritoneum and the diaphragm. In: Rumack CM, Wilson SR, Charboneau JW, editors. Diagnostic Ultrasound. St Louis: Mosby-Year Book; 1991.

16. Dinkel E, Lehnart R, Troger J, Peters H, Dittrich M. Sonographic evidence of intraperitoneal fluid. An experimental study and its clinical implications. Pediatr Radiol 1984; 14:299-303.

17. Thomas JR, Gunten CF. Diagnosis and management of Ascites; Principles \& practice of palliative care \& supportive oncology 3rd edition. Page no. 186-191.

18. Clark JH, Fitzgerald JF, Kleiman MB. Spontaneous bacterial peritonitis. J Pediatr 1984; 104:495-500.

19. Larcher VF, Manolaki N, Vegnente A, Vergani D, Mowat AP. Spontaneous bacterial peritonitis in children with chronic liver disease: clinical features and etiologic factors. J Pediatr 1985; 106:907-912.

20. Haghighat M, Dehghani SM, Alborzi A, Imanieh MH, Pourabbas B, Lalani M. Organisms causing spontaneous bacterial peritonitis in children with liver disease and ascites in southern Iran. World $\mathbf{J}$ Gastroenterol 2006; 12:5890-5892.

\section{How to cite this article?}

Talawar K, Ramesh R Pol, Yelamali B. C. Clinical profile of ascites in children at tertiary care hospital, North Karnataka. Int J Pediatr Res.2016;3(6):410-415.doi:10.17511/ijpr.2016.i06.07. 